\title{
Factors Influencing the Night Market Traders' Performance in Malaysia
}

\author{
Fauzilah Salleh ${ }^{1}$, Noryati Yaakub ${ }^{1}$, Kamariah Yunus ${ }^{2}$, Mazuri Abd Ghani ${ }^{1} \&$ Wan Kuntom Wan Sulong ${ }^{3}$ \\ 1 Faculty of Business Management and Accountancy, Universiti Sultan Zainal Abidin, Kuala Terengganu, \\ Malaysia \\ ${ }^{2}$ Faculty of Languages and Communication, Universiti Sultan Zainal Abidin, Kuala Terengganu, Malaysia \\ ${ }^{3}$ Faculty of Islamic Contemporary, Universiti Sultan Zainal Abidin, Kuala Terengganu, Malaysia \\ Correspondence: Fauzilah bt Salleh, Faculty of Business Management \& Accountancy, Universiti Sultan Zainal \\ Abidin, Gong Badak Campus, 21030 Kuala Terengganu, Terengganu, Malaysia. Tel: 60-9-666-4466. E-mail: \\ fauzilah@unisza.edu.my
}

Received: March 28, 2012 Accepted: April 23, 2012 Online Published: July 16, 2012

doi:10.5539/ijbm.v7n14p32 URL: http://dx.doi.org/10.5539/ijbm.v7n14p32

\begin{abstract}
This study was conducted to identify the factors affecting the night market traders' sales performance. The factors examined were the financial resources, consumers' tastes and preferences, product demands, business life span, and number of employees. This study tested seven hypotheses identified as the seven predictive factors influencing the performance of the night market traders' sales. The major factors influencing the sales performance of the night market traders were found to be the number of employees and business life span. The findings of this study can be used by other researchers to conduct a comparative study in this area besides providing advisory services to traders and potential traders who wish to do business in night markets.
\end{abstract}

Keywords: night market traders, sales performance, Micro, Small and Medium Enterprises (MSMEs), retail business, Ninth Malaysia Plan (9MP)

\section{Introduction}

Micro, Small and Medium Enterprises (MSMEs) in Malaysia are regarded as a rapidly growing industry and which stimulate and contribute towards the national economic development objectives. This industry produces a variety of jobs that require skills and education, strengthen the family ties in the community, prevent the loss of population, attract expertise and investment in the community, and create lasting stability (Minoo \& Charles, 2003). MSMEs are defined as companies that have full-time employees not exceeding 150 persons and annual sales not exceeding RM 25 million. There are several factors which either directly or indirectly influence the development of MSMEs in Malaysia. Government assistance schemes are considered as an important factor in promoting MSMEs. For example, the government has allocated RM 1.1 billion through the Ninth Malaysia Plan (9MP) as a provision for support. The Malaysian Prime Minister in his 9MP budget speech urged the MSMEs in Malaysia to produce and process the products innovatively, build a business that looks ahead, make use of sophisticated technology, and accumulate enough capitals. In addition to the government's aid, environmental changes such as globalization and technology development also stimulate the development of MSMEs in Malaysia. Under the 9MP, all MSMEs are encouraged to look ahead and make investments in innovative products, make use of recent technology, produce skillful workers and process products efficiently to ensure that the development of new products and services are continuant to compete in the global market.

The Development Council of Small and Medium Enterprises (DCSMEs) of Malaysia (2010) defined micro company as a company that has an annual sale of less than RM200, 000.00 and has full-time employees of less than five persons. Sharma, Miller, and Reeder (1990) in his study defined micro business as a company that is characterized as: (1) be implemented and managed by one or two employees, (2) usually established by the family, and (3) the functions are in the informal sectors. The factors that develop micro business include innovative resources, opportunities for new products and services, and infrastructural supports from private and public companies. From the definition, among the sectors identified under this category are hawkers markets covering public and private, group stalls, and the night market traders. The government has recognized the 
hawkers and night markets as one of the important economic activities carried out in many places in Malaysia. It is also a sector that has proven capable of providing retail services to the users and channeling the supply of goods and customer services. Night market trading activity is contributing to the Micro, Small and Medium Enterprises (MSMEs), which has economic value. The role played by the night market traders is very large for the economic upturn. According to Dictionary of the House, generating economy means to provide, produce or manufacture, and produce a country's economic wealth. Halvorson and Raundi (1992) also add that micro-businesses have economic values; they generate incomes and outputs, provide easy job opportunities, use domestic inputs, and produce cheap products or services. Night market is a place of retail business which is categorized as a market / moving stalls, the stall arrangement which extends down the road and makes use of public or private sites (Muhammad Fisal Ibrahim \& Soh Kok Leng, 2003). Night market business is also defined as night market hawking activities even though it is semi-static or seasonal. This user- commodity business runs a wide range of food and non food items that operate once or twice a week at different places. The existence of night markets is caused by the supply and demand of the night market traders. Night markets provide the opportunity for night market traders to earn extra income and for the buyers, night markets can help them acquire the diversity of daily necessities at low prices. Among the variety of daily necessities in the night market night market made popular by all levels of society are kitchen essential items (wet and dry goods), clothing, fruits, food, drinks and a few other items.

Based on the SME Annual Report 2009/2010, there are almost 99\% (550,000 companies) of the existing companies in Malaysia are the SMEs which the majority of them $(80 \%)$ are from micro companies. Of these, $87 \%$ of them are the services enterprises, seven per cent are manufacturing establishments and six per cent in agricultural sector. Majority of micro enterprises are in the service line. This industry is only accounted for $6 \%$ of the Gross Domestic Product (GDP) and 7.7\% of employment. This contribution is significantly lower than the global average of $80 \%$ of SMEs which contribute to $50 \%$ of GDP. Given the level of SME contribution to GDP is only $6 \%$, it indicates that the sector has a low performance. Therefore, this study aims to investigate the factors that contribute to the development of the existing micro sector. In particular, the objectives of this study are to determine the level of night market traders' selling and to identify the factors influencing the performance of the night market traders.

This study is important due to several reasons. First, the performance of the night market traders is a significant factor in the development of MSMEs because it helps in business growth. The results of the study will also help the night market traders in general and MSMEs entrepreneurs in particular, to get information and directions of their role in developing the business and thus contributing to the GDP. Second, the results of this study are important to assist government institutions such as SIRIM, Entrepreneur Development Foundation, and SMIDEC in providing guidance in the form of research to MSMEs entrepreneurs to meet future needs, allocating financial assistance, establishing awareness programs and retail sales description, and holding ongoing research so that innovations can be implemented and MSMEs can work in tandem with Malaysia's economic activities. Lastly, it is important to identify the factors that contribute to the success of MSMEs and thus to the economy.

\section{Literature Review}

\subsection{Measurement of Night Market Traders' Performance}

There are many ways to measure the performance of a micro business. Minoo and Charles' (2003) studies on economic development and micro enterprises in rural communities measured the performance of the micro industry through sales, profits, market share and future stability in the study of micro-businesses. Meanwhile, Brown, Shona, and Kathleen Eisenhardt (1995) measured success based on financial performance, including profitability, sales and market share. According to Wasilczuk (2000), it is difficult to measure progress and success of small businessmen and the measurement can be performed both objectively and subjectively. Objective measurement is difficult for it is hard to obtain information about the quantity of quality of a company's profits for such information may give an impact on the achievement of the company. Subjective measurement, on the other hand, is quite simple for it only requires simple information about assessment and business behaviors.

Knowles \& White (1995) found that revenues and profits are the two factors used to develop a small business where the outcome in question is the amount of cash received from sales or services rendered (Gaber, Davidson, Stickney and Weil, 1993). Meanwhile, Stranger (1998) used sales as a measure of performance easily understood by the respondents. Since there is no consensus on the best measurement of business performance in business research, a measure must be chosen and for the purpose of this study, researchers will be using annual sales as a measure of performance. 


\subsection{Factors Influencing MSMEs Performance}

The factors which influence the MSMEs performance vary in the literature. The structure-conduct performance (SCP) framework was used traditionally to explain the factors that influence firm performance. The framework contends that the structure of the market influence the conduct of the firm in the market, which is determined by the firm performance (Ferguson, 1993). Recently, many factors have been found to relate to business performance. Minoo and Charles (2003) conducted the study on economic development and rural micro-businesses from the retail sector, service and small manufacturing business in which ownership was different from individual ownership, partnership, family and co-operative ownership. This study emphasized the various categories of critical resources such as expertise, finance, logistics, security, and examined the importance of gender to the business and its impact on life expectancy and the success of micro-businesses in rural areas. The results showed that expertise in business such as marketing, strategic planning, and financial category plus the technical resources are critical to the success and long life of rural micro businesses. According to Miller and Grace (1990), business success depends on several factors. Among them are to learn and understand the market factors, customers' tastes and preferences, the number of goods used and customers' salaries. Meanwhile, Chittithaworn, Islam, Keawchana and Mohd Yusuf (2011) showed that SMEs' characteristics, customers and markets, the way of doing business, resources and finance, and external environment were the most significant factors influencing business performance.

Researchers also looked into the financial resources as the variables to identify the business performance. According to Thompson Lighthouse \& Co. (1996), entrepreneurs usually will get financing from the bank to start a business. Financial institutions at this time can give an answer either accepted or rejected in a short time a few weeks after the credits form is submitted (Howard, 2000). Meanwhile, Bradley (2000) noted in his research that some small businesses had gone bankrupt due to inadequate financial resources to continue their business.

Another factor was the age of business. The age of business increases in line with the age of business owners. If a business is able to continue operations beyond the initial period and grow business in five years, one might say that the business has been successful (Gray \& Gray, 1994). Orser and James (1992) found that the longer the business is in operation, the more the workers will work and thus increasing the annual income of the business. The study on the business age related to the firm performance was conducted by Rosli Mohd (2011). He looked at the factors affecting the performance of SMEs in the Malaysian auto-parts industry. The results showed that the firm age and foreign equity are significantly related to the performance of the firms. Another study looked into the business experience increased in parallel with the age of traders (Salleh, Yaakub, Mohamad, A.Ghani and W.Sulong, 2012) proved the age of the business have significant differences with the sales performance.

Last but not least, the number of employees also contributes to the business performance. Business owners' and employees' involvement in improving the production or services plays an important role in determining the success of a business. Thibault (2001) found that more and more workers who are employed full-time will generate higher sales because each member of the organization has a role and expertise in their work that contributes to business performance.

\section{Research Methodology}

\subsection{Research Setting}

This study was conducted to identify the factors that influenced the sales performance of the night market traders in Terengganu. This study was conducted in seven (7) districts of Terengganu, Malaysia comprising three (3) areas classified as urban, agriculture and fishery. The selection area was based on the following justifications: (1) Urban areas were selected according to the night market trading conducted in the urban areas of each district, (2) Agricultural areas were chosen based on the night market trading conducted in agricultural areas and rural areas in each district where the activities are focused on agriculture and (3), the fishery areas were opted according to the night market trading conducted in coastal areas where the majority of people carry out the activities related to fishing.

\subsection{Research Instruments}

The research instruments employed in this study were mainly the questionnaires. The questionnaires used in this study consist of two parts; Section A: Demographic questionnaires for merchants and businesses and Section B: Survey questionnaires on business factors.

\subsubsection{Section A: Demographic Questionnaires for Merchants and Businesses}

This section contains 10 questions pertaining to the respondents including gender, age, educational level, area, type of business, start-up capital and business life span by using the close-ended question format (close- ended 
questions) that required the respondents to answer the questions by choosing the respected scale. This method is suitable and convenient for questioning, reducing interview bias, making it faster to be administered, and easy to be answered by the respondents. This method also provides high uniformity of responses and ultimately facilitates data processing (Kinnear and Taylor, 1996).

\subsubsection{Section B: Survey Questionnaires on Business Factors}

This section involves collecting data on business factors seen to influence the sales performance consisting of 11 questionnaires on financial resources, consumers' preferences, product demands, start-up capitals, business life span, and the number of employees.

During the interviews conducted, a set of questionnaires was used to record the data. The questionnaires used in this research were adapted from those developed by Marc Thibault (2001) and were divided into two parts. The first section is to obtain demographic information about the business owners. The next section is to examine the factors influencing business performance using the Likert scale ranging from 1 (Extremely Disagree) to 5 (Strongly Agree). The data gathered from the questionnaires were transferred and analyzed using the Statistical Package for Social Science (SPSS) Version 14.0. The test validity (Cronbach coefficient alphas) was performed on all instruments and the most important thing was to test the hypotheses formed earlier. The correlation analysis was performed to determine the relationship between the dependent variables, annual sales and the number of independent variables in the hypotheses. Finally, regression analysis is used to determine the factors that affect the performance of the night market traders. In this quantitative research design, the descriptive and regression analysis were used to analyze the data. According to Tabachnick and Fidell (1996), regression analysis can be used to obtain the best prediction equation to almost all phenomena related to independent variables and dependent variables. Regression analysis was also used because it enables researchers to assess the best relationship between the dependent variables, sales, and a few independent variables mentioned in the hypotheses.

\subsection{Pilot Study}

A pilot study was conducted to test the questionnaires, to determine the reliability of the items used in the questionnaires and the validity of measuring instruments to ensure that it is exactly what has to be measured. This pilot study was conducted on 20 businessmen in one of the state in Malaysia. The feedbacks obtained from the questionnaires were further analyzed using SPSS and the reliability coefficient alpha scores for each dimension were presented in Table 1. According to Nunnally (1978), the reliability coefficient of not less than 0.5 is usually acceptable, thus the questionnaires used are considered acceptable in terms of reliability coefficient.

Table 1. Reliability coefficient values (Cronbach Alpha)

\begin{tabular}{lc}
\hline Dimensions & Reliability coefficient values $(\mathrm{N}=20)$ \\
\hline Financial Resources & 0.6909 \\
Consumer Tastes & 0.6555 \\
Demands & 0.6667 \\
Start-up Capitals & 0.7250 \\
Number of Employees & 0.8555 \\
\hline
\end{tabular}

\subsection{Census of Hawkers}

In this field research, the samples were selected using a convenience sampling. The interviews were carried out by the four researchers to ensure the respondents answered the questions precisely and the data were then recorded exactly based on the answers provided by the merchants. Before this, the researchers had made several field visits and censuses. The areas within the districts visited were based on the data provided by the district councils throughout the state of Terengganu, Malaysia. A total of 350 night market traders were interviewed.

\section{Findings}

A total of 350 questionnaires were processed and only 286 (81.7\%) can be used for analysis because some of the questions asked were partly answered by the respondents. This section presents the results of the study on the profile of night market traders and businesses including sex, age, levels of education, type of business, traders' 
age, start-up capitals, business locations, and business incomes.

\subsection{Night Market Traders' Profiles}

From a total of 286 questionnaires analyzed, it was found that $53.1 \%$ was male traders while $46.9 \%$ were females. From the figures, the majority of them (93\%) were the Malays. The remaining $0.7 \%$ was the Chinese and $6.3 \%$ were from different races especially the Cambodians. In terms of age, the majority of the traders $(85 \%)$ were in the middle age (26-55 years) and $8 \%$ was in the age group above 55 years old and the oldest aged 70 years. This shows the needs to stay in business for survival purposes. Regarding the levels of education, most traders had a low level of education, ranging from not attending school at all to the primary school leavers (33.6\%), secondary school leavers $(63.9 \%)$ and only $2.4 \%$ are educated traders (possessing the diplomas and degrees).

\subsection{Analysis of the Sales Performance}

Some night market traders (42\%) earned less than RM50, 000.00 per annum. 33.6\% of the traders earned the annual sales between RM50, 000.00 to RM99, 999.00 followed by $14.0 \%$ of the traders obtaining the annual sales of RM100, 000.00 to RM149 999.00 . About $4.9 \%$ of the night market traders earned the annual sales between RM150, 000.00 to RM199, 999.00 followed by 5.6\% of them gained the annual sales exceeding RM200, 000.00. And out of this percentage, one night market trader even managed to gain the annual sales of RM546, 000.00 . These clearly show that the night market traders were able to generate very high sales (see Table 2 ).

Table 2. Night market traders sales performance $(n=286)$

\begin{tabular}{llc}
\hline \multicolumn{1}{c}{ Variables } & Percentage (\%) \\
\hline Annual Sales & Less than RM49,999 per year & 42.0 \\
& RM50,000 to RM99,999 per year & 33.6 \\
& RM100,000 to RM149,999 per year & 14.0 \\
& RM150,000 to RM199,999 per year & 4.9 \\
& Exceeding RM200,000 per year & 5.6 \\
\hline
\end{tabular}

\subsection{Inferential Analysis}

The second objective of this study is to identify the factors that influenced the performance of the night market traders. Seven hypotheses were constructed as follows:

H1: There is a significant relationship between sales performance and financial resources.

$\mathrm{H} 2$ : There is a significant relationship between sales performance and consumers' tastes and preferences for the products.

H3: There is a significant relationship between sales performance and product demands.

H4: There is a significant relationship between sales performance and business life span.

H5: There is a significant relationship between sales performance and the number of employees.

H6: There is a significant relationship between sales performance and the amount of start-up capital.

H7: There is a significant relationship between sales performance and the frequency of weekly trading.

In order to answer the second research objective; that is, to identify the factors contributing to the night market traders' sales performance, regression analysis was employed in analyzing the predictor variables. The summary findings of the analysis were shown in Table 3. It was found that five out of the seven predictor variables were associated with the sales performance with a significant value of $F(286)=11.63, \mathrm{p}<0.001$. The influence of predictor variables on the sales performance can be explained by the adjusted $\mathrm{R}^{2}$ value of 0.255 . This means that the predictor variables can inform about $25.5 \%$ of the sales performance and the remaining percentage is explained by other factors which were not controlled and determined in this study.

According to Lea (1997) the extent to which independent variables are good in explaining the relationship with dependent variables can be determined by the adjusted $\mathrm{R}^{2}$ value. According to her, the adjusted $\mathrm{R}^{2}$ value of more than $75 \%$ is very good, $50 \%-75 \%$ is good, $25 \%-50 \%$ less good but acceptable and less than $25 \%$ is bad. In this 
study, the adjusted $\mathrm{R}^{2}$ value shows a bad relationship but it still indicates the existence of the relationship between the independent and dependent variables.

Table 3 also showed that five out of the seven predictor variables had a significant influence on the sales performance. This significance was shown by the predictor factors such as product demands, $\beta=0203, p<0.05$, business life span, $\beta=0168, p<0.05$, the number of employees, $\beta=-0197, p<0.001$, start-up capitals, $\beta=0177$, $p<0.05$ and the frequency of weekly trading, $\beta=0312, p<0.001$. This shows that product demands, business life span, the number of employees, and the frequency of weekly trading play an extremely important role, compared to other predictor variables, in contributing to the sales performance. Therefore, the hypotheses 3, 4, 5, 6 and 7 were supported while the hypotheses 1 and 2 were rejected.

Table 3. The relationships between the predictor variables and sales performance

\begin{tabular}{lcc}
\hline Variables & Beta (B) & Sig F \\
\hline Financial Resources & -0.009 & 0.876 \\
Consumers' tastes & -0.044 & 0.574 \\
Product Demands & 0.203 & $0.009^{*}$ \\
Business Life Span & 0.168 & $0.005^{*}$ \\
Number of Employees & -0.194 & $0.000^{* *}$ \\
Start-up Capitals & 0.177 & $0.002^{*}$ \\
Frequency of Weekly Trading & 0.312 & $0.000^{* *}$ \\
\hline $\mathrm{R}^{2}$ & 0.279 & \\
Adjusted $\mathrm{R}^{2}$ & 0.255 & \\
F Value & 11.635 & \\
Sig F & 0.000 &
\end{tabular}

\section{Conclusions and Recommendations for Future Research}

The factors that influenced the sales performance of the night market traders were examined in this study. This study tested the seven hypotheses theorized as influencing the sales performance of the night market traders and the two hypotheses were rejected. The predictive factors noting as influencing the traders' sales performance included product demands, business life span, the number of employees, the amount of start-up capital, and the frequency of weekly trading. The findings of this study can be used by other researchers to do comparative studies besides providing advisory services to traders and potential traders who wish to do business in night markets.

Since this study was able to support the existing theory and other related studies, it is very important to examine in detail how this business operates in comparison to other micro industries. Future research must focus on the same predictive variables and compare the findings with this study. The follow-up research is important to be held to look for changes in business practices to see improvement in the future.

As the independent variables employed in this study were taken from the previous studies and the interpretation of the results were based on the overseas researchers living in different contexts, some follow-up research is crucial to be conducted to examine the consistency of the findings with local contexts. Moreover, the follow-up study should be held qualitatively to explore in-depth about the local night market traders' working culture and trends to understand clearly the aspects and types of business contributing to high sales performance. This way, the results in the qualitative research concerning the business values and beliefs could be compared with those in the quantitative research.

\section{References}

Baines, S., \& Wheelock, J. (1998). Working for each other: Gender, the household and micro-enterprise survival and growth. International Small Business Journal, 17, 16-35. http://dx.doi.org/10.1177/0266242698171001 
Bradley, D. (2002). Lack of financial and location planning causes small business bankruptcy. University of Central Arkansas.

Brown, S. L., \& Eisenhardt, K. (1995). Product development: Past research, present findings, and future. The Academy of Management Review, 20(2), 343-379. http://dx.doi.org/10.5465/AMR.1995.9507312922

Chittithaworn, C., Islam. M. A., Keawchana, T., \& M. Yusuf, D. (2011). Factors Affecting Business Success of Small \& Medium Enterprises (SMEs) in Thailand. Asian Social Science, 7(5), 180-190. http://dx.doi.org/10.5539/ass.v7n5p180

Coleman, S. (2000). Access to capital and terms of credit: A comparison of men and women owned small businesses. Journal of Small Business Management, 38(3), 37-52.

Ferguson, P. R. (1993). Industrial economics: issues and perspectives. Hong Kong: Mac millan.

Gaber, B., Davidson, S., Stickney, C., \& Weil, R. (1993). Financial Accounting (5th ed.). Toronto: Holt, Rinehart, and Winston of Canada.

Gray, D. M., \& Gray, D. (1994). The Complete Canadian Small Business Guide (2nd ed.). Toronto: McGraw-Hill.

Halvorson, Q. R. (1992). The growing Potential of Micro-Enterprises. Organisation for Economic Cooperation and Development.

Harper, M. (1984). Small Business in the Third World: Guidelines for Practical Assistance. New York: John Wiley.

Heck, R., Rowe, B., \& Owen, A. (1995). Home Based Employment and Family Life. Westport, Connecticut: Auburn House.

Howard, R. (2000). Personal Interview: Small Business Financing. Royal Bank of Canada.

Ibrahim, M. F., \& Leng, S. K. (2003). Shoppers' perceptions of retail developments: Suburban shopping centres and night markets in Singapore. Journal of Retail \& Leisure Property, 3, 176-189. http://dx.doi.org/10.1057/palgrave.rlp.5090174

Kinnear, T. C., \& Taylor, J. R. (1996). Marketing Research: An Applied Approach (5th ed.). New York, NY: McGraw-Hill.

Knowles, R., \& White, D. (1995). Issues in Canadian Small Business. Toronto: Harcourt Brace \& Company Canada.

Lighthouse, T. (1996). Canadian Sources of Financing for SMEs. In D. Lavoie (Ed.), ICSB Bulletin.

Miller, H. G., \& Grace, L. (1990). Global aspects of local micro-enterprise development. Journal of Studies in Technical Careers, 12(1), 27-37.

Minoo, T., \& Charles, S. (2003). Economic development and micro-enterprises in rural communities: Are there gender differences?. The Journal of Business and Economic Development, 9(1), 26-41.

Nunnally, J. C. (1978). Psychometric theory (2nd ed.). New York: McGraw-Hill.

Okurut, F. (2008). Determinants of Microenterprise Performance in Uganda. The IUP Journal of Agricultural Economics, 2008(1), 77-87.

Orser, B., \& Foster, M. (1992). Home Enterprise: Canadians and Home Based Work. The Home Based Business Project Committee, Canada.

Orser, B., \& James, T. (1992). Home Business: The New Reality. Home Based Business Project Committee, Canada.

Rosli Mohd. (2011). Determinants of small and medium enterprises performance in the Malaysian auto-parts industry. African Journal of Business Management, 5(20), 8235-8241.

Salleh. F., Yaakub. N., Mohamad. M, A., Ghani. M. W., \& Sulong. W. K. (2012). Demographic Characteristics Differences and Sales Performance among Night Market Traders in Malaysia. International Business Journal, 5(4), 25-33. http://dx.doi.org/10.5539/ibr.v5n4p25

Sharma, M., Miller, H. G., \& Reeder, R. (1990). Micro-enterprise growth: Operational models and implementation assistance in Third and Fourth world countries. Journal of Small Business Management, 28(4), 9-21.

SME Annual Report. (2011).

Stranger, A. (1998). Determinants of Home-Based Business Sales Performance (Master Dissertation). University of New England, Australia. 
Tabachnick, B. G., \& Fidell, L. S. (1996). Using Multivariate Statistics. NY: HarperCollins.

Thibault, M. (2001). Influencing Sales Performance in Small and Medium-Sized Enterprise (Master Dissertation). The University of Guelph, Ontario.

Wasilczuk, J. (2000). Advantageous Competence of Owner / Managers to Grow the Firm in Poland. Journal of SmallBusiness Management, 38(2), 88-90. 